\title{
Validation of ECMWF Sea Level Pressure Analyses over the Bellingshausen Sea, Antarctica
}

\author{
J. C. KING \\ British Antarctic Survey, Natural Environment Research Council, Cambridge, United Kingdom
}

6 October 2002 and 27 December 2002

ABSTRACT

\begin{abstract}
Surface pressure measurements from instruments deployed on ice floes in the southern Bellingshausen Sea were used to assess the accuracy of European Centre for Medium-Range Weather Forecasts (ECMWF) analyses in this region during February-May 2001. Despite the lack of in situ observations from this region, the analyses were found to be in very good agreement with the observed pressures and pressure gradients. The absolute difference between observed and analyzed pressures never exceeded $2.7 \mathrm{hPa}$ over a pressure range of 965-1000 $\mathrm{hPa}$. Standard deviations of the differences between observed and analyzed pressures were typically around 1 $\mathrm{hPa}$. When additional in situ surface pressure observations from this region became available for use in the analyses, the agreement between analyzed and observed pressures improved only slightly. This suggests that atmospheric analyses are constrained well by satellite temperature soundings and other remotely sensed data in this region.
\end{abstract}

\section{Introduction}

The Pacific sector of the Southern Ocean is almost devoid of any in situ meteorological observations. Atmospheric analyses in this region are largely constrained by satellite sounder data together with surface and upper-air observations from coastal Antarctic stations. The region is, however, of considerable interest to climatologists because interannual variability of the Southern Hemisphere atmospheric circulation peaks in this sector (Connolley 1997). Lachlan-Cope et al. (2001) demonstrated that interaction of the high-latitude Southern Hemisphere circulation with the nonaxisymmetric orography of Antarctica contributed to the high degree of variability observed in this sector. However, there are also strong indications that variability associated with ENSO is strongest over this sector of the Southern Ocean (Cullather et al. 1996). The west coast of the Antarctic Peninsula has warmed faster than any other part of the Southern Hemisphere over the past 50 years, and it is possible that atmospheric circulation changes in the South Pacific sector have contributed to this warming (King 1994; Vaughan et al. 2001).

Atmospheric analyses produced by global numerical weather prediction (NWP) centers are potentially of great value in studying atmospheric circulation variability. However, in regions for which there are few

Corresponding author address: Dr. J. C. King, British Antarctic Survey, High Cross, Madingley Rd., Cambridge CB3 OET, United Kingdom.

E-mail: j.c.king@bas.ac.uk meteorological observations to constrain NWP models, it is important to verify that the analyses faithfully reproduce the regional atmospheric circulation. This verification attempt requires access to independent validation data that were not assimilated into the model used to produce the analyses. Few such data are available for the South Pacific sector of the Southern Ocean, and so little is known about the reliability of NWP analyses in this region. Turner et al. (1999) compared operational analyses in the Antarctic region from a number of NWP centers with satellite imagery and concluded that all of the analyses were capable of resolving the major synoptic-scale systems around the Antarctic. However, they noted significant differences between analyses in data-sparse regions such as the Amundsen and Bellingshausen Seas. Cullather et al. (1996, 1997) compared ship observations of surface pressure in the Amundsen and Bellingshausen Seas during 1993 and 1994 with NWP analyses and found a reassuring degree of agreement.

This paper reports the results of a validation study carried out using surface pressure observations from instruments deployed on ice floes in the southern Bellingshausen Sea during early 2001. Data from these instruments were used to assess the accuracy of atmospheric analyses produced by the European Centre for Medium-Range Weather Forecasts (ECMWF). A1though limited in temporal and spatial extent, the study provides unique quantitative information on the accuracy of NWP analyses in this region. 


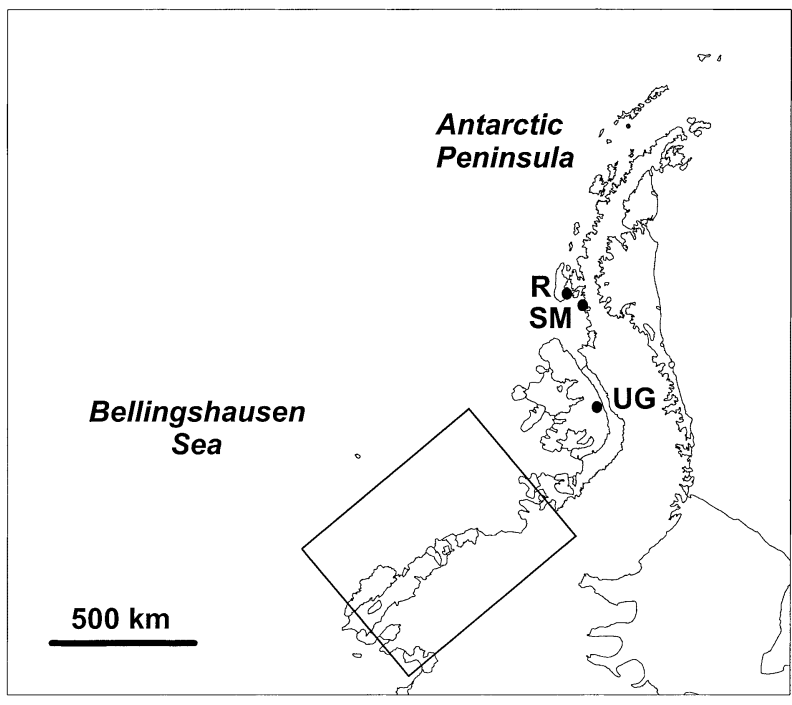

FIG. 1. A map of the Antarctic Peninsula and Bellingshausen Sea The area in which the CALIB deployments were made (shown in detail in Fig. 2) is indicated by the boldface rectangle. Meteorological observing stations referred to in the text are R, Rothera; SM, San Martin; and UG, Uranus Glacier Automatic Weather Station.

\section{Methods}

Surface pressure data were obtained from compact air-launched ice beacons (CALIBs, manufactured by Metocean, Inc.) deployed on ice floes. The CALIB is a simple and robust instrument package that comprises a barometric pressure sensor (Setra 276), an internal temperature sensor, and a transmitter for the "ARGOS" satellite data collection and location system. Lithium batteries provide up to 12 months of operation. CALIBs are equipped with parachutes to enable deployment from aircraft onto ice floes. The manufacturers quote an overall system accuracy of $\pm 1 \mathrm{hPa}$ for the pressure measurement, and ARGOS locations are accurate to about $\pm 500 \mathrm{~m}$. At the latitude of the deployments (around $70^{\circ} \mathrm{S}$ ), the ARGOS system has excellent temporal coverage, and pressure data were typically available at 12 -h intervals. The pressure data were not made available on the Global Telecommunications System (GTS) of the World Meteorological Organization (WMO) and thus provide an independent source of information for validating atmospheric analyses.

Two sets of deployments were made in the southern part of the Bellingshausen Sea during 2001 (Fig. 1). On 18 February 2001, three CALIBs were deployed from a British Antarctic Survey aircraft onto old ice floes remaining at the end of the 2000/01 austral summer. One of these (ARGOS ID 21384) failed shortly after deployment, probably as a result of the floe on which it landed breaking up. A second CALIB (ARGOS ID 21388) functioned until 4 March. The third CALIB (ARGOS ID 21376) functioned until 15 March, when transmissions became very sporadic. Transmissions resumed on 25 March, but the pressure sensor appeared to have

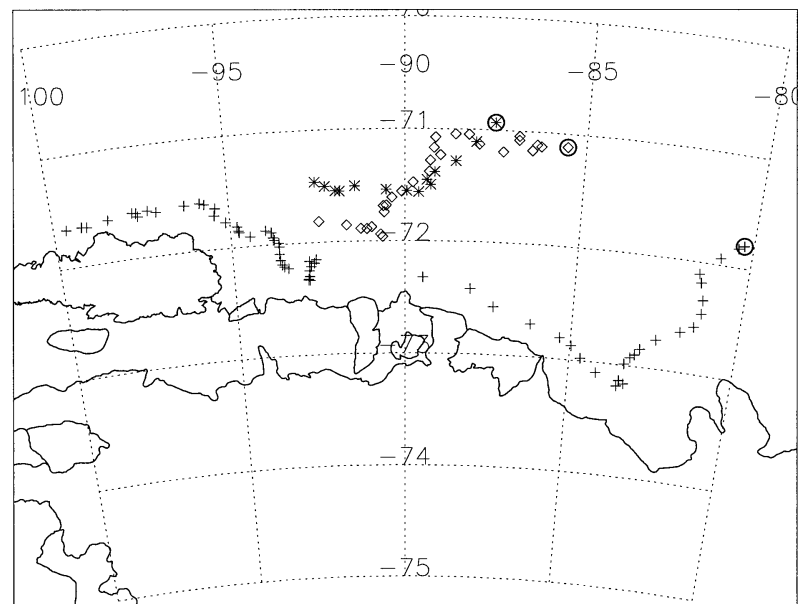

FIG. 2. Drift tracks of the three successful CALIBs. Each symbol marks the CALIB position at 0000 UTC: "plus" signs for CALIB 21376, 18 Feb-3 May 2001 (no data between 15 and 25 Mar); asterisks for CALIB 21388, 18 Feb-4 Mar 2001; and diamonds for CALIB 21392, 23 Apr-21 May 2001. The initial position for each CALIB is ringed.

been damaged in the intervening period, and so no useful pressure data were available after 15 March. CALIB 21376 finally ceased transmitting on 3 May.

A fourth CALIB (ARGOS ID 21392) was deployed directly onto an ice floe in the growing winter pack ice from the Research Vessel Polarstern on 23 April 2001. This unit provided data until it ceased transmitting on 21 May. Deployment positions and drift tracks for all successful CALIB deployments are shown in Fig. 2.

Data from the CALIBs were obtained from the ARGOS processing center in Ramonville, France. After inspection and manual removal of any clearly erroneous pressure and position data, observations falling within $\pm 1 \mathrm{~h}$ of UTC hours 0000, 0600, 1200, and 1800 were extracted. Sea level pressure data, interpolated to the CALIB position, were then extracted from ECMWF 6hourly operational analyses for each of these observations.

The ECMWF forecast system employs a global spectral model that, in early 2001, was run at a triangular truncation of TL511 (equivalent to approximately 40$\mathrm{km}$ horizontal spacing) with 60 levels in the vertical direction. Data used in this study were supplied on a $1.125^{\circ} \times 1.125^{\circ}$ latitude-longitude grid. The analysis employs a four-dimensional variational data assimilation scheme to assimilate a wide variety of observational data, including conventional surface and upper-air observations and remote sensing data such as satellite temperature soundings and sea surface winds derived from scatterometer measurements.

\section{Results}

In the period during which the CALIBs were operational, the weather in the study area was characterized 


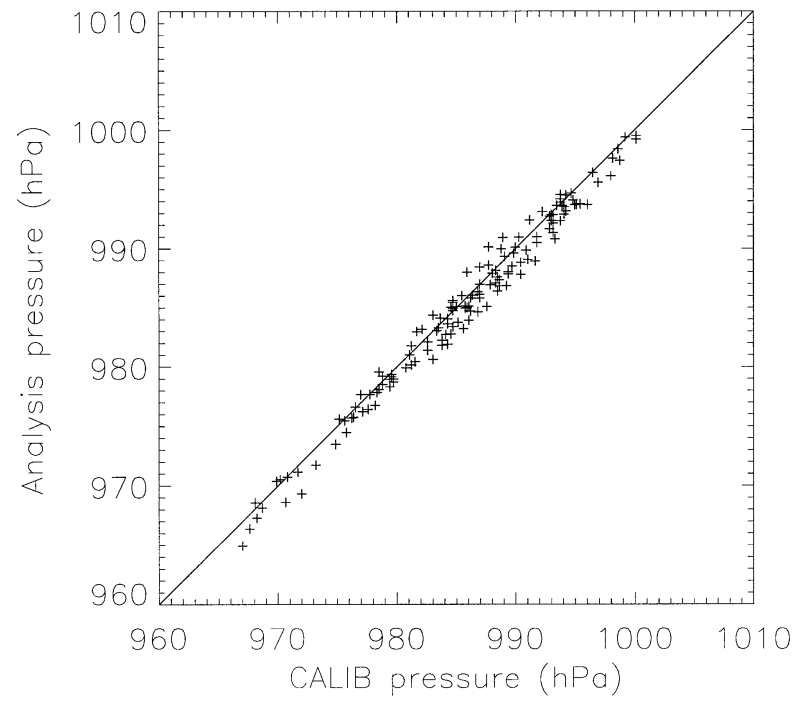

FIG. 3. Surface pressure recorded by CALIBs 21376 and 21388 vs ECMWF-analyzed surface pressure interpolated to the CALIB 1ocations over the period 18 Feb-15 Mar 2001. Data points are indicated by crosses; the line indicates perfect agreement.

by a series of cyclones moving from west to east across the Bellingshausen Sea and subsequently becoming nearly stationary as they ran up against the Antarctic Peninsula. This circulation pattern drove the generally southward and westward movement of the CALIBs seen in Fig. 2. Central pressures of the cyclones were mostly in the range of 950-970 $\mathrm{hPa}$ in the ECMWF analyses.

Pressure measurements from CALIBs 21376 and 21388 are compared with ECMWF pressures interpolated to the CALIB location in Fig. 3. The absolute difference between measured pressure and interpolated analyzed pressure never exceeds $2.7 \mathrm{hPa}$. The excellent agreement between measured and analyzed pressures is confirmed by the statistics shown in Tables 1 and 2 . Analyses made at 0000 and 1200 UTC fit the observations slightly better than do those made at 0600 and 1800 UTC. The difference in mean bias between the two sets of analyses is significant at the 5\% level (using a $t$ test and allowing for autocorrelation of the data); the standard deviations are not significantly different using an $F$ test.

Measurements from CALIB 21392 provide a useful baseline against which the goodness of fit of the earlier

TABLE 1. Mean, standard deviation, and maximum modulus of the difference between surface pressure measured by CALIB $21376\left(p_{c}\right)$ and ECMWF-analyzed sea level pressure interpolated to the same location $\left(p_{a}\right)$ for 18 Feb-15 Mar 2001.

\begin{tabular}{lcccc}
\hline \hline \multicolumn{1}{c}{ Analyses } & $\begin{array}{c}\text { Mean } \\
\left(p_{c}-p_{a}\right) \\
(\mathrm{hPa})\end{array}$ & $\begin{array}{c}\text { Std dev } \\
\left(p_{c}-p_{a}\right) \\
(\mathrm{hPa})\end{array}$ & $\begin{array}{c}\text { Max } \\
\left|p_{c}-p_{a}\right| \\
(\mathrm{hPa})\end{array}$ & No. obs \\
\hline All & 0.53 & 1.02 & 2.70 & 95 \\
0000 and 1200 UTC & 0.31 & 0.96 & 2.50 & 49 \\
0600 and 1800 UTC & 0.76 & 1.05 & 2.70 & 46 \\
\hline
\end{tabular}

TABLE 2. Same as Table 1 but for CALIB 21388 for 18 Feb-4 Mar 2001.

\begin{tabular}{lcccc}
\hline \hline \multicolumn{1}{c}{ Analyses } & $\begin{array}{c}\text { Mean } \\
\left(p_{c}-p_{a}\right) \\
(\mathrm{hPa})\end{array}$ & $\begin{array}{c}\text { Std dev } \\
\left(p_{c}-p_{a}\right) \\
(\mathrm{hPa})\end{array}$ & $\begin{array}{c}\text { Max } \\
\left|p_{c}-p_{a}\right| \\
(\mathrm{hPa})\end{array}$ & No. obs \\
\hline All & 0.78 & 1.09 & 2.67 & 52 \\
0000 and 1200 UTC & 0.72 & 1.08 & 2.36 & 25 \\
0600 and 1800 UTC & 0.87 & 1.11 & 2.67 & 27 \\
\hline
\end{tabular}

deployments to the analyses can be judged. Shortly after CALIB 21392 was deployed, three surface velocity profiling barometers (SVPBs, manufactured by Metocean, Inc.) were deployed approximately $135 \mathrm{~km}$ farther north. The pressure observations from the SVPBs were transmitted on the GTS (WMO IDs 71513, 71582, and 71583 ) and were thus available to constrain the ECMWF analyses. Comparison of CALIB 21392 measurements with ECMWF pressures (Table 3) shows little change in the mean difference and a small reduction in its standard deviation. The standard deviation of the analysisCALIB pressure difference is less than the 1-hPa system accuracy of the CALIB pressure measurements, indicating that measurement and interpolation errors may be the dominant contribution to analysis-observation difference in this case.

A more stringent test of the analyses is the accuracy with which they reproduce observed pressure gradients (or geostrophic winds). This metric can be tested over the 12-day period during which CALIBs 21376 and 21388 were both operational. Over this period, the separation of the two CALIBs increased from 275 to 367 $\mathrm{km}$. Figure 4 shows the observed pressure difference between these two CALIBs in comparison with the difference in analyzed pressure interpolated to the CALIB locations. The agreement is good, with a maximum absolute difference of $3.35 \mathrm{hPa}$ between observed and analyzed pressure difference. The standard deviation of the difference (Table 4) is equivalent to a geostrophic wind speed of about $2 \mathrm{~m} \mathrm{~s}^{-1}$.

\section{Discussion}

Although limited in scope both spatially and temporally, the observations presented in this note suggest that ECMWF analyses represent the surface pressure field over the southern Bellingshausen Sea to a high degree of accuracy despite the lack of in situ meteo-

TABle 3. Same as Table 1 but for CALIB 21392 for 23 Apr-21 May 2001.

\begin{tabular}{lcccc}
\hline \hline \multicolumn{1}{c}{ Analyses } & $\begin{array}{c}\text { Mean } \\
\left(p_{c}-p_{a}\right) \\
(\mathrm{hPa})\end{array}$ & $\begin{array}{c}\text { Std dev } \\
\left(p_{c}-p_{a}\right) \\
(\mathrm{hPa})\end{array}$ & $\begin{array}{c}\text { Max } \\
\left|p_{c}-p_{a}\right| \\
(\mathrm{hPa})\end{array}$ & No. obs \\
\hline All & 0.78 & 0.75 & 2.30 & 105 \\
0000 and 1200 UTC & 0.84 & 0.81 & 2.19 & 53 \\
0600 and 1800 UTC & 0.71 & 0.68 & 2.30 & 52 \\
\hline
\end{tabular}




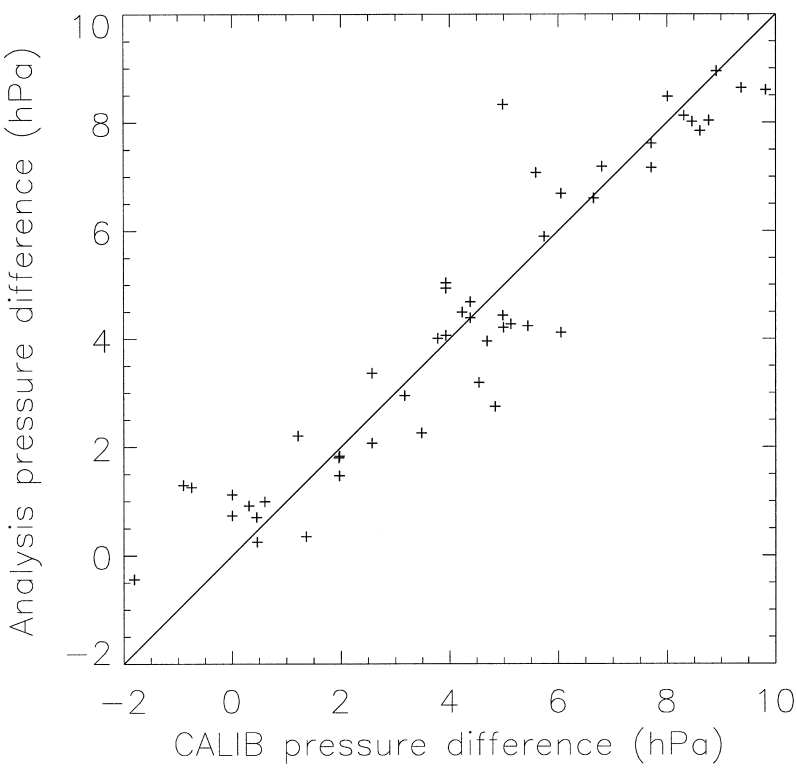

FIG. 4. Measured pressure difference between CALIBs 21376 and 21388 vs the corresponding pressure difference in ECMWF-analyzed surface pressure between 18 Feb and 4 Mar 2001. Data points are indicated by crosses; the line indicates perfect agreement.

rological observations from this region to constrain the analyses. The nearest observations available were from an automatic weather station at Uranus Glacier, Alexander Island, and from the Rothera and San Martin stations in the northern part of Marguerite Bay (see Fig. 1 for locations). The Antarctic coast is devoid of meteorological observations for over $1000 \mathrm{~km}$ to the west of the study area. Apart from the SVPB measurements described above, no ship or buoy observations were available south of $60^{\circ} \mathrm{S}$ in this sector of the Southern Ocean.

In the absence of in situ observations, the analyses are largely constrained by satellite sounder data, together with scatterometer-derived surface winds over ice-free areas of the ocean. This study suggests that such data are sufficient to enable NWP data assimilation schemes to represent the surface pressure field over this sector of the Southern Ocean to a high level of accuracy. The availability of pressure data from the SVPBs after the April deployments resulted in only a small improvement in the fit of the analyses to the independent CALIB measurements. Although care must be taken in comparing two short periods that could have very different inherent predictability, the absence of any marked improvement in fit suggests that these additional observations had little impact on analyses that were already constrained well by satellite data.

Although the accuracy of the present-day analyses has been demonstrated, it cannot be assumed that analyses made in earlier years were of equivalent quality. Satellite sounder data first became available in 1972. Since then there have been significant improvements
TABLE 4. Mean, standard deviation, and maximum modulus of the difference between the difference in surface pressure measured by CALIBs 21376 and $21388\left(\Delta p_{c}\right)$ and the difference in ECMWF-analyzed surface pressures interpolated to the same locations $\left(\Delta p_{a}\right)$ for 18 Feb-4 Mar 2001.

\begin{tabular}{|c|c|c|c|c|}
\hline Analyses & $\begin{array}{c}\text { Mean } \\
\left(\Delta p_{c}-\Delta p_{a}\right) \\
(\mathrm{hPa})\end{array}$ & $\begin{array}{c}\text { Std dev } \\
\left(\Delta p_{c}-\Delta p_{a}\right) \\
(\mathrm{hPa})\end{array}$ & $\begin{array}{c}\operatorname{Max} \\
\left|\Delta p_{c}-\Delta p_{a}\right| \\
(\mathrm{hPa})\end{array}$ & No. obs \\
\hline All & 0.02 & 1.11 & 3.35 & 50 \\
\hline 0000 and 1200 UTC & -0.11 & 0.92 & 2.20 & 25 \\
\hline 0600 and 1800 UTC & 0.15 & 1.28 & 3.35 & 25 \\
\hline
\end{tabular}

both in the instruments themselves and in the ways in which satellite data are used in preparing atmospheric analyses, leading to a marked improvement in the quality of analyses in the Southern Hemisphere since the mid-1990s (Simmons and Hollingsworth 2002). Cullather et al. (1996) studied the accuracy of ECMWF operational surface pressure analyses in this same sector of the Southern Ocean using independent ship observations from August and September of 1993. They found that the analyses represented the main synoptic variations in pressure very well, with a standard error of less than $5 \mathrm{hPa}$ for the difference between ship observations and interpolated analysis values. This value is somewhat larger than the values found in the current study, indicating that, consistent with the findings of Simmons and Hollingsworth (2002), the quality of analyses over this sector of the Southern Ocean may have improved considerably between 1993 and 2001. Given the complete absence of in situ data from this sector, analyses for years before 1972, during which year satellite data first became available, are likely to be of questionable quality.

Acknowledgments. I thank the British Antarctic Survey Air Unit and the Operations Team at the Rothera research station for their assistance with the February 2001 CALIB deployments. The April 2001 deployments were carried out by M. Doble, Scott Polar Research Institute, using facilities on F/S Polarstern provided by the Alfred Wegener Institute, Bremerhaven, Germany. Doctors W. M. Connolley and G. J. Marshall provided assistance with data processing. Operational analyses were provided to the British Antarctic Survey by ECMWF as part of the ECMWF special project "Assessment of ECMWF Forecasts over the High-Latitude Areas of the Southern Hemisphere."

\section{REFERENCES}

Connolley, W. M., 1997: Variability in annual mean circulation in southern high latitudes. Climate Dyn., 13, 745-756.

Cullather, R. I., D. H. Bromwich, and M. L. VanWoert, 1996: Interannual variations in Antarctic precipitation related to El Niño Southern Oscillation. J. Geophys. Res., 101, 19 109-19 118. _ _ _ , and R. W. Grumbine, 1997: Validation of operational 
numerical analyses in Antarctic latitudes. J. Geophys. Res., 102, $13761-13784$.

King, J. C., 1994: Recent climate variability in the vicinity of the Antarctic Peninsula. Int. J. Climatol., 14, 357-369.

Lachlan-Cope, T. A., W. M. Connolley, and J. Turner, 2001: The role of the nonaxisymmetric Antarctic orography in forcing the observed pattern of variability of the Antarctic climate. Geophys. Res. Lett., 28, 4111-4114.

Simmons, A. J., and A. Hollingsworth, 2002: Some aspects of the improvement in skill of numerical weather prediction. Quart. J. Roy. Meteor. Soc., 128, 647-677.

Turner, J., S. Leonard, G. J. Marshall, M. Pook, L. Cowled, R. Jardine, S. Pendlebury, and N. Adams, 1999: An assessment of operational Antarctic analyses based on data from the FROST project. Wea. Forecasting, 14, 817-834.

Vaughan, D. G., G. J. Marshall, W. M. Connolley, J. C. King, and R. M. Mulvaney, 2001: Devil in the detail. Science, 293, 17771779 . 